Jones, P.D. (2008), The European Institute of Technology and the Europe of Knowledge: a research agenda, Globalisation, Societies and Education, Vol. 6, No. 3, pp. 291-307.

The European Institute of Technology and the Europe of Knowledge

\author{
A Research Agenda
}

\author{
Peter D. Jones \\ Centre for Globalisation, Education and Societies \\ Graduate School of Education \\ University of Bristol \\ 35 Berkeley Square \\ Clifton \\ Bristol \\ BS8 1JA
}

p.d.jones@bristol.ac.uk 


\title{
The European Institute of Technology and the Europe of Knowledge
}

\author{
A Research Agenda
}

Peter Jones*

University of Bristol, UK

This paper explores the development and significance of the European Institute of Technology(EIT) in the period since 2005 when the European Union launched a suite of initiatives for Higher Education, Research and Innovation, including the EIT, as part of attempts to re-launch its Lisbon Strategy around a 'Growth and Jobs' agenda. The EIT is presented as implicated in European Commission attempts to redefine the mandates and governance of Higher Education institutions as part of a Knowledge Based Economy route to economic and social development. The production and contestation of the EIT as it was negotiated within EU institutions is shown as having been conditioned by the interactions between Commission attempts to use the EIT to disrupt the governance and financing of Higher Education and Research and national and institutional determination to constrain the EIT within extant governance and financing principles. In conclusion, the paper outlines a research agenda for the study and analysis of the EIT in the period up to 2013 which will make it possible to specify the significance of the EIT for EU integration, the development of the European Higher Education, Research and Innovation fields, the fate of EU strategies for capital accumulation and social development and the legitimacy of the EU itself.

Keywords: European Union; The Lisbon Strategy; Higher Education; Research; Innovation; The European Institute of Technology

\footnotetext{
* Email: p.d.jones@bristol.ac.uk
} 


\section{Introduction}

The establishment of the European Institute of Technology (EIT) during 2008 is an important event. An initial attempt to define its significance is provided by Gornitzka et al (2007, p. 198), in terms of what it represents for the construction of the EU level of capacity for redefining the purposes and practices of higher education and research:

'The EIT is a proposal for common capacity building at the European level: building an academic institution with (semi) permanent staff, resources and a different kind of research organisation than the model for European research collaboration embedded in the R\&D Framework Programme. Creating a common University organization that combines teaching and research is an innovation in the European context with respect to traditional ways of thinking about and organising research. It is an unfolding experiment in research organisation comparable to previous attempts in the earlier history of European integration.’

The argument developed in this paper is that in addition to the focus on the EU level, attempts to understand the developing significance of the EIT need to engage with broader concerns about Knowledge Based Economy models for economic and social development, the role of the higher education and research sectors within global processes and the destabilising implications of an EIT model for national and institutional processes. In addition, analysis of the discursive and institutional struggles around the launch of the EIT, help to provide the means to frame the significance of the EIT securely within a sense of the ongoing struggles with regard to the contradictions and dilemmas of both the development of EU capacity to influence national and institutional processes and the legitimacy of EU economic and social strategies.

The paper starts by placing the EIT within the ongoing attempts to articulate and implement an EU level development model, the Lisbon Strategy (European Council, 
2000). The EIT is presented as a part of attempts which began in 2005 to re-launch the Lisbon Strategy around a 'Growth and Jobs' agenda (European Council, 2005a). Central to these attempts was the need to live up to Lisbon agendas by promoting institutional, financial and mandate innovations for Higher Education and Research of which the EIT is a part. 'Growth and Jobs' Lisbon is then investigated in terms of the way in which European Commission agendas for Higher Education interacted with national agendas in ways which demonstrated the terrain upon which the negotiation and launch of the EIT would develop. In the next section, the documents, negotiations and decisions which resulted from attempts to launch the EIT between 2006 and 2008 are analysed so as to identify both the ambition of the EIT as initially conceived and what is revealed about the contradictions between national, institutional and European Commission agendas in the development of an EU institution, the EIT. Finally, the story of the attempts to launch the EIT is used as a way to specify the expected and predictable aspects of the EIT as it develops between 2008 and 2013 which will constitute a research agenda for ongoing attempts to understand and explain its significance.

\section{The EIT and 'Growth and Jobs' Lisbon}

The 'Growth and Jobs' Lisbon strategy sought to streamline what was presented as the overloaded and contradictory policy agenda which developed after the launch of the Lisbon Strategy by the EU in 2000. The hubristic Lisbon Strategy was to see the EU become by 2010 'the most competitive and dynamic knowledge-based economy in the world, capable of sustainable growth with more and better jobs and greater social cohesion' (European Council, 2000). By 2005 the Strategy had stalled and the EU's Mid- 
Term Review sought to identify both why this had happened and what should be done about it. The result was a relaunch of the Lisbon Strategy around a focus on policies and initiatives for growth and jobs, an overhauled governance arrangement with Integrated Guidelines for economic and employment policies at the EU level and national action plans at the Member State level. 'Growth and Jobs' Lisbon drew upon the work of a High Level group under the chairmanship of Wim Kok (Kok,2004) and a Communication from the President of the Commission, José Manuel Barroso (European Commission, 2005a). ${ }^{1}$ For Collignon (2006), the stakes could not have been higher: the grandiose dreams of Lisbon 2000 were the subject of increasing ridicule, the implementation gap, rather weakly construed as a problem of political will, would mean that 2010 would come and go with the few concrete targets established by Lisbon 2000 left unmet. Unless some clear and achievable measures were introduced, the Lisbon Strategy and perhaps even the EU would 'die a slow death by gridlock, economic stagnation and un-kept promises' (Collignon, 2006, p. 32). Some sense of the significance of the EIT can then be gained by seeing it as part of the high-stakes attempts to achieve outcome legitimacy for not only the Lisbon Strategy but also the EU level and its promise of a Knowledge Based economy route to economic and societal development.

1 For Ludlow (2005), it is important to recognise that the 'principal mover and shaker at political level behind the Commission's work on the Lisbon Strategy in 2004-2005 was undoubtedly Günter Verheugen, the German vice-president, whose portfolio covered enterprise and industry' (p.17). The relaunch of the Lisbon Strategy around a 'Growth and Jobs' agenda can be seen as a move into the terrain of industrial strategy and a neo-Mercantilist tendency within the range of capital accumulation projects which have been articulated with one another since the 1986 launch of the Single Market (Van Apeldoorn, 2006) 
The priority given within 'Growth and Jobs' Lisbon for increases in productivity, the production and application of new technology and consequently the achievement of more and better jobs, was to produce inter alia, the establishment of new institutions. To an extent then, the fate of the Lisbon Strategy was to be determined by the establishment of ever more institutional capacity at the EU level. The Kok Report called for an intensified focus on the importance and means of achieving one of the specific Lisbon Strategy targets: the achievement of an EU level of R\&D investment set at $3 \%$ of GDP. To achieve this, Kok called for the mobilisation of EU and Member State funding and an intensification of links between public and private sources of funding:

'Particularly on key technologies that drive economic growth both to strengthen the science base and to increase the leverage effect on R\&D investment by the private sector. Public-private partnerships should be facilitated and encouraged as a means of boosting investment. Europe's science base should be strengthened by funding and coordinating long term basic research ranked by scientific merit via the creation of a European Research Council. At the same time, Member States and the Commission should look at ways in which public procurement could be used to provide a pioneer market for new research and innovation-intensive products and services. In addition, increased efforts should be mobilised at national and EU level by all concerned stakeholders to promote technological initiatives based on Europewide public-private partnerships'

(Kok , 2004, p. 21)

The European Commission went even further (European Commission, 2005a) in calling for a suite of initiatives involving EU scale strategic selection of research and innovation 'winners', substantially increased spending from the EU budget on 'Growth and Jobs' policies, the establishment of new institutions and the explicit linking of initiatives with a 
drive to complete the formation of the distinct European Higher Education area to embed new institutions, new funding and EU governance of higher education with research and innovation strategies (See Table 1).

Consideration of the European Institute of Technology needs then to begin with recognition of its relationships to the 'Growth and Jobs' Lisbon agenda, the other initiatives launched at the same time and the ongoing importance of Higher Education as education, research and source of innovation in the construction of a Knowledge Based Economy route to sustainable capital accumulation (Jessop,2004). Clearly though, the EIT is only a part of the attempt through intensified EU integration of higher education,

\begin{tabular}{|l|l|}
\hline \multicolumn{1}{|c|}{ Strategy } & \multicolumn{1}{c|}{ Policy } \\
\hline 'Picking Winners' & - Information Society \\
& - Biotechnology, \\
& - Eco-innovation \\
\hline Funding & - Public/Private 3\% GDP for R\&D \\
& - Research Framework Programme \\
& - Programme for Competitiveness and Innovation \\
& - Reform of State-aid Policy \\
& - Tax environment for R\&D \\
\hline Institutions & - European Institute of Technology \\
& - European Research Council \\
& - Innovation Poles \\
& - European Technology Initiatives \\
\hline Governance & - Completion of European Higher Education Area \\
\hline
\end{tabular}

(Table 1. 'Growth and Jobs' Lisbon for Education, Research and Innovation)

research and innovation to achieve Lisbon goals and through them the economic and social development which will provide the legitimacy for contemporary forms of economic development. Some sense of how important a part the EIT constitutes is provided by the financial means which are to be mobilised. The EU Budget settlement of 
2007-2013 allocates 5.3\% of the total EU budget for Research, the Research Framework Programme 7 receives a 41\% increase compared to Programme 6 and all of this takes place within a context where EU plus Member State R\&D spending is expected to reach 2.6\% of GDP by 2010 (Amos, 2007a). The European Research Council (ERC) itself accounts for 7.5 billion Euro for the period 2007-20013 (Amos, 2007b). ${ }^{2}$ The EIT budget as eventually established in 2007, was to be 2.4 billion Euro during the 2007-2013 budget settlement (European Council, 2007). Clearly then, the EIT budget while not insignificant, is in monetary terms perhaps more significant for what it suggests about a developing model for higher education, research and innovation links rather than for in terms of financial capacity.

At the same time, the launch of the European Research Council and its developing activities in relation to the EIT, constitute an important touch stone for consideration of the significance of the EIT. The suite of 'Growth and Jobs' initiatives combined begin to take on the form of quite dramatic shifts with established EU practices in this area which have always followed the principles underlying the EU's distribution of the Structural Funds. These embedded principles of pan-European and cooperative transfer of knowledge, technology and capacity, which in essence are principles of redistribution, do not apply for the ERC. As Amos (2007b) says, the ERC breaks with established practices in a number of significant ways:

\footnotetext{
${ }^{2}$ The EIT budget as established in 2007, is to be 2.4 billion Euro during the 2007-2013 budget settlement (European Council, 2007).
} 
'Research projects will not have to be collaborative - they do not have to be panEuropean even. There will be no specification of research areas or themes. There will be no 'juste retour' which sees member states get back a 'fair proportion' of the monies they put into the funding pot'

(Amos, 2007b)

For Traynor (2007), shifts in these distributional principles are of even greater significance for the prospects for EU legitimacy. For him, 'the great unsung success story of the EU over the decades has been its social democratic exercise in redistributing wealth between and within countries, narrowing wealth gap and hugely benefiting states such as Greece, Portugal, and Ireland. In essence this meant that big, wealthy Germany kept the chequebook open.' What the 'Growth and Jobs' initiatives potentially represent then is a rather fateful commitment to the concentration of EU and national funding rather than to its redistribution with the attendant consequences for economic and social cohesion at all scales through the EU. In practice of course, the story of the launch of the ERC provides a perspective on the embedded tensions which can be expected to play a part in the construction and contestation of the implications of such fateful shifts. The UK example provides a useful starting point for this. Historically, the UK has gained $15 \%$ of total available spending under Research Framework Programmes 1- 6 (Amos, 2007a). National expectations of benefiting from changed regulations can be expected to play a significant part in the degree of acceptance, promotion and bargaining around the new arrangements. In terms of the ERC, it was famously the then British Science Minister Lord Sainsbury who threw his weight behind the ERC because of its novelty in terms of removing the pan-European collaborative requirements and the ERC focus on basic research rather than applied research (Amos, 2007b). Both the ERC and the EIT can be 
expected though to reveal the underlying tensions and dynamics as EU level initiatives disrupt the 'political, juridical, administrative, economic and cultural sovereignty of the nation-state in the field of R\&E' (Trondal, 2002, p. 350). As is explored below, the Commission Communications on the EIT, both explicitly and implicitly set out to challenge national state capacity in all of these area. Part of the significance of the EIT then has to be addressed in terms of what it reveals at EU, national and institutional level about the interactions between 'Growth and Jobs' Lisbon's development of a road to Knowledge Based Economy development, the concentration of financial and institutional capacity and national and institutional strategies and processes.

\section{'Growth and Jobs' Lisbon and Higher Education}

In addition to the broader significance of the EIT in terms of the place of research and innovation within the Lisbon Strategy model for economic development within the EU, analysis needs to engage with EU strategic ambitions for Higher Education institutions. For Robertson (forthcoming 2008), the period since 2005 has seen 'a massive injection of new and renewed policies levered into place in order to produce an ideational, representation, institutional and relational shift in the modern European university' (p. 11). ${ }^{3}$ The construction of higher education as an object of EU scale policy activity since 2005, is centrally framed by the declaration of the centrality of the knowledge triangle. At

3 Robertson's sense is that the Mid-Term review marks a dramatic shift in emphasis for Higher Education. Still, it is important to recognise that 'Growth and Jobs' Lisbon has legitimated an intensification of attention for policy areas which were already present within the original Lisbon strategy. The argument here is that the novelty comes with the development of an EU level focus on the institutions of Higher Education, their governance and attempts to disrupt them at a range of scales. 
the EU level it is the agenda of capital accumulation, not legitimation or social reproduction, which is addressed. ${ }^{4}$ The functional and scalar distribution of the governance of education (Robertson and Dale, 2003), has increasingly found less place at the EU scale for the broader objectives of higher education within the master discourse of competitiveness within the Knowledge Based Economy.

The positions adopted with regard to Higher Education institutions by the Commission since 2005 have been increasingly strident and assertive. There has been an intensification of attention to the construction of the modern European university as an 'other,' often presented in derisory terms. So for example, in the 2005 Communication, 'Mobilising the Brainpower of Europe: Enabling Universities To Make Their Full Contribution To The Lisbon Strategy (European Commission, 2005b), it is the norms and values of higher education which are addressed where:

'A tendency to uniformity and egalitarianism in many national systems has ensured that the average quality of universities, while generally homogenous, is comparatively good - at least academically’

(European Commission, 2005b, p. 3)

The discourse of derision comes through clearly: 'uniformity' 'egalitarianism' and even being comparatively good 'academically' or no longer the norms and values which are sufficient. And this discursive presentation with associated policy priorities has been

${ }^{4}$ See Dale (1989) for an examination of how education policy initiatives have to respond to these different requirements and how they do so in necessarily unstable and contradictory ways. 
central to attempts to disrupt accepted norms, values, institutions, discourses and practices. Universities are constructed as servicing the needs of the 'same group of academically best-qualified learners- which leads to the exclusion of those who do not conform to the standard model' and a systematic aversion to 'centres of world-class excellence’ (European Commission, 2005b, p. 4). Disruption is central to the ambition of this discourse; disruption of disciplinary, institutional and national boundaries and the primary target is the state. It is the state which over regulates, the state which is inflexible, the state which produces uniformity. This is a project for innovation and disruption and implicitly for the removal of the national state from its regulatory role and a fundamental reconstruction of its funding role. So for example, 'where change is always a matter for legislation, reforms are bound to be few, disruptive and uniform'(European Commission, 2005, p. 4) and 'most universities are strongly dependent on the state and ill-prepared for worldwide competition over talent, prestige and resources’(European Commission, 2005b, p. 4).

The notion of disruption particularly in terms of disrupting established scales of the governance of Higher Education institutions, runs throughout the analysis of the 'Mobilising Brainpower' text. The disruption extends to the university itself. Excellence is not about entire universities but about faculties, teams and networks; the scalar discourse goes hand in hand with a disaggregation. At the same time, the opposite movement is also prevalent: the construction of the European space, of European Universities and their relationship with the needs of the European economy as making both necessary and inevitable the establishment of the EU scale as dominant in the 
governance of Higher Education. The EU role for higher education is akin to its role for failing industries of the past:

'The EU has supported the conversion process of sectors like the steel industry or agriculture; it now faces the imperative to modernise its 'knowledge industry' and in particular its universities'

(European Commission, 2005b, p. 10)

The language throughout is of the University, not as a politically and socially rich domain of complex social relations, but as an industry, a brand, a commodity in the competitive market. The assertion of the nature of the enterprise, what the university is and what it is for, is entirely through this optic of the market and of competition. ${ }^{5}$ It is not that the other dimensions of universities are not recognised, they are just, in keeping with the priorities of 'Growth and Jobs' Lisbon, dependent for their maintenance and defence on the success of capital accumulation within a Knowledge Based Economy.

The global competition for brains is central to the discourse and the rationale. Given that 'about 400,000 Europeans with a scientific and technical education are currently living in America, of whom about 120,000 are employed as researchers’ (European Commission, 2005b, p. 15), policies now have to address the return of brains, the recruitment of brains and the mobilisation of brains for innovation, productivity and capital accumulation.

5 So the Communication asserts that: 'Except for the few which have built up their own brand names, Europe's universities need quality seals with international credibility. Failure to develop such seals would perpetuate for them a competitive disadvantage' (European Commission, 2005b, p. 7) 
Commission Communications are of course a part of the range of policy document genres within the EU. Their presentation is the first stage in the production of EU policy and EU funded initiatives and their production is dependent on what happens during discussion and negotiation with the Council of Ministers structures and eventually with the European Parliament. The 'Mobilising Brainpower' Communication became a Council Resolution (European Council, 2005b). The Council position endorsed the role of policies for 'knowledge, innovation and the optimisation of human capital (ibid. p. 1) and restates the importance of 'excellence', 'worldwide quality reference' and making it possible to 'compete against the best in the world.' This becomes the established EU discursive position from which higher education is viewed. At the same time, the Resolution 'shares the view that' it is important to improve performance in terms of attainment, access and research in comparison with other regions and countries in the world and that universities need to adapt and change so as to enhance their quality, attractiveness and relevance to society. The core dimensions of the 'Growth and Jobs' Lisbon agenda for Higher Education have become EU policy. At the same time, the EU policy provides the opportunity for Member States to insert their national priorities into the discourse. The commitment to encourage universities to 'develop stronger partnerships with the society around them, including local communities and the business world,' crucially provides the opportunity for Member States to define which of these are relevant in terms of national policy preferences. The sharing of discourses at the EU scale goes hand in hand with considerable variation in national contexts and national priorities. And of course these come very much to the fore the closer policy comes to the construction of particular institutions with considerable implications in terms of funding 
and the intrusion of the EU scale into the 'complex ecology of processes and determinants’ (Gornitzka et al, 2007, p. 183), at the national scale.

If analysis of the significance of the 'Growth and Jobs' initiatives for Higher Education, Research and Innovation always in the end results in the need to recognise the importance of national and institutional dilemmas and contradictions in constructing and contesting the institutional and mandates of EU institutions and funding, this becomes even more the case when a particular sector, in this case Higher Education, is implicated in attempts to disrupt both discursively and materially the extant processes and determinants of the scales of governance. It is to the implications of this that attention needs to turn as the EIT is launched and developed.

\section{EIT as Discourse and Practice}

\section{EIT - The Consultation Document}

In the aftermath of the launch of 'Growth and Jobs' Lisbon, work began within the European Commission on fleshing out the very slight sketch of a project for the EIT. A working group was established involving Commission officials from three Directorate Generals: DG Enterprise, DG Research and DG Education and Culture. DG Enterprise took the lead and the group prepared a Consultation Document prior to a consultation process which ran from September to December 2005. 
The first public appearance of the EIT in anything like its finished form then came with the distribution of 'A European Institute of Technology Consultation Document' (European Commission, 2005c). In keeping with the higher education policy documents produced since 2005, the document is long on descriptions of failure, indeed of derision, of Europe's performance in education, research and innovation. The script is one of decline and forthcoming eclipse in the light of challenges from the traditional competitors, the USA and Japan, and the rise of 'the coming players in the game of knowledge', China and India. ${ }^{6}$ The language of the document is rich with examples of the kind of innovation-speak which betrays the origins of the EIT in the Enterprise DG with Europe presented as needing to 'take action to regain its position as a leading player' (European Commission, 2005c, p. 1). The construal of the Higher Education sector is particularly derisive. The language of failure, fragmentation and isolation is epitomised by the rather tired trope of the 'Ivory Tower'. The EU is constructed as being potentially overwhelmed by the numerical advantages of the Asian economies with China alone producing 'more maths, science and technology graduates each year than the whole of the EU put together' (European Commission, 2005c, p. 2). In fact, of course, the production of Maths, Science and Technology graduates is the least of Europe's problems. As part of the Lisbon Strategy, the EU established five benchmarks for education and training policy. One of the benchmarks was to increase the number of Maths, Science and

${ }^{6}$ The story of decline is supported by the assertion that the numbers of Nobel Prize winners has decreased from 73\% in the period 1901 to 1950, to 19\% between 1995-2004. Between 1992 and 2001 US patents increased while EU patents decreased. No mention here then of the kind of caveats provided by Kok who identified EU strengths in civil aerospace, mobile phones and power engineering while pointing out that 'too much of US technological advantage is concentrated in defence and defence-related sectors' (Kok, 2004, p. 20). 
Technology graduates in 2010 by 15\% compared to 2000 figures and it was achieved in 2003 (European Commission, 2005d, p. 14). As a result it is far harder to construct the laggard status of the EU's productivity and growth performance in terms of the failure to produce sufficiently skilled graduates. ${ }^{7}$ Nonetheless, the discourse of threat and crisis (see Robertson, this issue) is used to justify the need for a transformation in the relationship between Higher Education, Research and Innovation. The EIT is to play a part in making it possible to 'bring out more of the commercial value in the research currently done in the EU' (Commission, 2005c, p. 2). In order to achieve this, the EIT is conceived of as a vehicle to bring together 'key players' from the academic world and the public and private sectors so as to create economies of scale, 'critical mass', for the production and application of knowledge.

If the ambition, to leverage private sector investment so as to exploit research for commercial profit, it rather a common place within the Innovation policy field, the implications of this in terms of establishing the EIT as a model for how to do it are rather more dramatic as well as sketchily conceived. For the purposes of the consultation, the Commission asserts that it has no fixed model in mind for what the EIT should look like, although this needs to be taken with more than a pinch of salt. Strategically, there was never any expectation that the EIT would be a physical institution; it was always

${ }^{7}$ For a presentation of the underlying causes of EU long-run difficulties in providing the conditions for a post-Fordist growth take-off, see Cafruny and Ryner (2007). , 
expected to take the form of a network of some sort. ${ }^{8}$ Nonetheless, it would be a particularly intensive form of network with specific aspirations in terms of the implications for governance, autonomy, sources of funding and articulation with extant forms of education, research and innovation at the full range of EU scales and globally. From the outset, the consultation process makes it clear that this should be something more than existing networks and different from other 'Growth and Jobs' initiatives such as Innovation Poles and Technology Platforms.

\section{EIT - 'First Cut' Communication}

Following the Consultation process, the Commission produced a Communication in February 2006. It is impossible to understand its rationale for the construction of the EIT without understanding the links it makes with innovation. So this 'First Cut' Communication identifies the innovation problems for which the EIT is constructed as a solution $^{9}$ :

‘Europe still falls short in turning R\&D results into commercial opportunities, developing a concentration of human, financial and physical resources in research and higher education, promoting an innovation and entrepreneurial culture in

8 See Corbett (2003), for the history of the long saga of the establishment of the European University Institute in Florence. The attempt to establish an EIT on such a basis would have been guarantee that nothing would be established for a considerable period of time. Institutional memory combined with recent experience of the establishment of Community institutions would presumably have ruled out this approach in the short-term whatever its ongoing attraction over the long-haul.

${ }^{9}$ The need for a further Communication after this 'First Cut' was due to the 'near universal hostility from scientific and education leaders' (Science, 2006, 1227) 
research and education, as well as in setting up new organisational models suited to today's needs'

(European Commission, 2006a, p. 2).

Such is the solution, but it comes with a quite remarkable degree of vagueness about the institution which will be created. It is more than a network but rather less than a university. It will have a 'virtual' form but with some highly material consequences for human and physical resources which are to 'seconded (not just networked) from existing organisations so that they become legally part of the EIT and can jointly develop an integrated strategy’ (European Commission, 2006a, p. 2) ${ }^{10}$. Quite how this would be expected to operate or to be accepted by eventual participants and their institutions is something of a puzzle. The implications for participating institutions were immediately recognised and challenged. In the UK, the concern was that these arrangements would undermine the research strategies of institutions such as Cambridge and Imperial College (The Guardian, 2006) and the perceived contradictions between EIT and ERC were a source of underlying scepticism (Science, 2006).

As an institution, the EIT as a whole was expected to be a 'knowledge operator, not a funding agency' (European Commission, 2006a, p. 12). Made up of networks designated as 'Knowledge Communities' which were expected to be self-selected and inter-

${ }^{10}$ The implications of secondment, the legal transfer for up to 15 years of infrastructure, staff and equipment, would have been enormous. The ambition can be measured by contrasting the Research Framework Programmes and their 7 year establishment within the EU budget settlement timetable, with this attempt to more than double the degree of financial and temporal commitment. 
disciplinary, they, or perhaps rather more importantly, the institutions from which they were to be drawn, would be motivated by the opportunity to benefit from enhanced visibility and prestige, to capture spill-overs into the home institutions, to respond to financial incentives including a share of intellectual property rights, and the potential for change agents within the home institutions and their national systems, to mobilise the effects of participation for broader changes.

In terms of governance too, the aim was for the institution to combine communities of science and business and for these relations to permeate throughout the institution. So the Communication sees the EIT as:

'Not to be constrained by the boundaries and obstacles which contribute to the fragmentation of European higher education and research today’

(European Commission, 2006a, p. 2)

In essence, this produced a series of recommendations for the regulation of the EIT, the legal status of the EIT and the intellectual property generated through the EIT which constituted a utopian project to disrupt and escape from the extant, nationally-based regulation of university research. The aim was to 'give the EIT its own legal personality and independence from national legislation. It will provide the framework to allow proper management and the necessary accountability to the EU institutions' (European Commission, 2006a, p. 3) What this amounts to is the ambition to construct a distinctive regulatory framework so as to produce a university and research culture in which 'selection as well as career is based on competition, paying for performance is not a 
taboo, and engaging in business is seen positively as an important learning opportunity in a researcher's curriculum' (European Commission, 2006a, p. 5). The Communication also articulates a cultural vision which constructs the EIT as a vehicle for the creation of a new kind of researcher, to create subjects who are able 'to traverse the 'cultural and intellectual gap between researchers and entrepreneurs' (European Commission, 2006a, p. 5). Central to this cultural vision is the systematic denial of any normative claims on the EIT beyond the pursuit of excellence with a commercial pay-off. Entirely stripped of any context other than the contribution to capital accumulation, the EIT will 'have no obligation to undertake actions which fail to meet the criterion of excellence' (European Commission, 2006a, p. 7) ${ }^{11}$ As a cultural project, the objectives are continually framed in terms of the 'other' of extant university research. Whereas 'many universities in Europe are essentially public services' (European Commission, 2006a, p. 8), the EIT is to be overtly different.

The construction of intellectual property as an object of EIT management was a further demonstration of the potential implications of the EIT. Given the long-standing inability of the EU to establish a Community Patent, the creation of the EIT as owner and manager of significant amounts of intellectual property throughout the EU, constitutes a striking example of policy entrepreneurship in the production of potential policy spillovers. ${ }^{12}$

11 The extent to which it is possible to strip functions away in this respect and how they creep back in, becomes central to the analysis of the processes of arriving at the Regulation which is pursued below.

12 The agreement on a Community Patent was a key aim in Lisbon (2000) and 'Growth and Jobs' Lisbon (2005), and yet by 2007, the Commissioner responsible, Charley McCreevy, could say that 'the proposal 
The stated criteria of success for the EIT clearly demonstrate the commercial and the cultural priorities of the Commission. Evaluations of success should consider:

'First, its ability to convince the private sector that it can deliver commercially relevant results. Second, the extent to which the universities and policy-makers take up the EIT model as a successful new organisational structure for universities'

(European Commission, 2006a, p. 8)

In terms of funding, the expectation was that the funding would come from the EU, Member States and the Business Community although the parameters of this were left extremely vague. ${ }^{13}$ Despite this vagueness combined with the rather unrealistic ambition, the core intentions of the EIT, to contribute to the production and application of knowledge for 'Growth and Jobs, were sufficiently widely shared at EU and National levels for the EIT to have a second chance at success despite the hostility to the detail of the EIT as provided in this 'first cut' presentation.

EIT - ‘SECOND BITE’ COMMUNICATION

Reaction to the Commission Communication led to the need for a second Communication in June of the same year (European Commission, 2006b). Significant elements of the

for an EU-wide patent is stuck in the mud. It is clear to me form discussion with member states that there is no consensus at present on how to improve the situation' (McCreevy cited in Jones,(2007))

${ }^{13}$ Experience of the Galileo project was presumably at the forefront of national responses to this vagueness given the propensity for these big projects to become the financial responsibility of the EU budget. The cost of Galileo, a 3.6 billion Euro project was expected to need a 1 billion Euro EU contribution but the EU needed to find an extra 2.4 billion to save the project after the private consortium pulled out of the project (Deutsche Welle, 2007). 
ambition remain in place but the means for achieving them are shifted in particular directions.

The EIT continues to be presented as providing the opportunity to 'not be merely a new operator in education, research and innovation, but a reference model, embodying the knowledge triangle at the European level' (European Commission, 2006b, p. 2) ${ }^{14}$ The ambition remains to go beyond extant forms of EU engagement with research and innovation, the EIT is emphasised as an 'integrated partnership' although the parameters of both integration and partnership remained contentious. The EIT would remain an autonomous institution and a sui generis one: ${ }^{15}$

'One of the key elements of the proposal is to ensure that the EIT should be an autonomous institution which will be free to determine, in line with its broad objective to be a force for excellent education, research and innovation, its own way of working'

(European Commission, 2006b, p. 4)

At the same time, the content of this autonomy and the relationships between component parts of the institution and their 'home' contexts, have shifted. The EIT itself is both the umbrella for the Knowledge Communities and a light and effective operational legal entity with a Governing Board and a limited support staff. The Governing Board would

\footnotetext{
${ }^{14}$ The discourse of reference modelling needs of course to be unpacked. Emulation needs to be restored to its relationship to practices and mechanisms of influence.
} 
select the Knowledge Communities and support them financially, it would provide the strategic goals, monitoring and accountability but the Knowledge Communities would be the focus in terms of 'integrated partnership.'

The degree of autonomy within the EIT institutions also shifts. Now the focus is on the Knowledge Communities in having 'considerable autonomy and maximum flexibility in their internal organisation and management of resources (financial, human and physical)' (European Commission, 2006b, p. 6). The idea of secondment has been modulated in terms of contractual relations within the Knowledge Community. ${ }^{16}$ At the same time, the Communication tries to hold on to the core ambition which is to create a relationship between individual researchers and teams and the EIT and to influence the regulation of the labour of research:

'A sufficient commitment from the staff working within the Knowledge Communities to the EIT itself, to its identity and to its ongoing success must be guaranteed at the selection stage, and it will be important to have a common employment framework (covering issues such as remuneration, working conditions, IPR etc.). Within that framework, Knowledge Communities should have the freedom to organise their human resources as is most appropriate'

${ }^{15}$ Although the discursive move to designate an institutional form as sui generis needs to be recognised as the strategic selective move that it is, seeking to silence particular forms of analysis and normative evaluation.

${ }^{16}$ The idea of secondment is presented as one in a range of alternatives which includes employment by the EIT or secondment with a variety of employment arrangements including rights of return, dual affiliation and temporary attachments. 
(European Commission, 2006b, p. 7)

At the same time, the Governing Board whose 'members should be nominated 'ad personam' with no representative function whatsoever' (European Commission, 2006b, p. 6), would retain significant capacity to operate according to the principles of the ERC with no responsibility other than to the education, research and innovation agenda.

The 'Second Bite' Communication actually amplifies the education component of the EIT. It is expected to be engaged in both teaching and research and to be able to award degrees. The potential significance of this in terms of articulations with the Bologna and Lisbon mobilisation of mechanisms for curriculum development, credit transfer and recognition of qualifications are clear.

In terms of funding, the EIT is still expected to develop its own financial capacity and its accumulation of a 'critical mass of EIT-managed IPR, would prove attractive to potential participants in the fields concerned' (European Commission, 2006b, p. 9). At the same time, the funding dynamics shift. The EIT is now expected to require 'substantial public funding' and 'public funding is likely to remain essential to the long-term development of concentrations of intellectual capital’ (European Commission, 2006b, p. 9).

The global dimension of the 'Growth and Jobs' agenda for Higher Education, the competition for global research talent, was always part of the ambition for a world class EIT. What is added here is an engagement with what that means in institutional terms. This Communication identifies the possibility for the EIT to capture 'research and innovation in third countries through appropriate links’ (European Commission, 2006b, 
p. 10) The possibility that the Knowledge Communities could include network teams and institutions from third countries constitutes a considerable ratcheting up of the potential for the EIT to not only lever-in the excellence from research activity in non-EU countries but also to lever it out of its national and institutional contexts.

\section{EIT - NEGOTIATING THE REGULATION}

What is particularly striking is that the 'second bite' Communication itself, needed to be changed in quite central ways before it could be presented to the Council in October 2006 as a Proposal for a Regulation (European Commission, 2006c).

In the Proposal, the EIT is presented in terms of how:

'Most Member States, albeit with different intensities, encounter difficulties in promoting an innovation and entrepreneurial culture in research and education, in developing critical masses of human, financial and physical resources in knowledge and innovation, and in rewarding performance and excellence in ways which attract the best academic staff and researchers'

(European Commission, 2006c, p. 2)

In keeping with this genre of document, the EU scale is legitimated in terms of the scale and nature of the challenges and how the EIT 'complements, facilitates and coordinates Member States’ policies and responses’ (European Commission, 2006c, p. 2) Of course the treaty caveats should not obscure the fact that the EIT as presented here would still have had significant disrupting rather than complementary effects. Nonetheless, the 
selected treaty base for the Regulation would be Article 157: 'specific measures in support of action taken in the Member States aimed a fostering a better exploitation of the industrial potential of policies of innovation, research and technological development' (European Commission, 2006c, p. 8). The competence of the EU in this area helps to remind us of the EIT's place within the EU and the 'Growth and Jobs' Lisbon policy field.

Discursively, the Knowledge Communities have become Knowledge and Innovation Communities (KICs), conceived of as 'joint ventures' between the private sector, the research community and excellent teams from research communities and universities. In a significant shift, it is now to be a relationship based on 'contractual arrangements, which will set out the KIC's rights and obligations, ensure an adequate level of coordination and outline the mechanism for monitoring and evaluation of the KICs activities and outcomes' (European Commission, 2006c, p. 4). In this proposal, the EIT is still intended to be a degree awarding university.

As subsequently became clear, the Proposal takes an altogether too sanguine view of the prospects for arriving at a financial framework for the EIT. The Proposal rather breezily considers that the 2.4 billion Euro cost over the 2007-2013 period would 'either come directly from the community budget, directly or indirectly through Community programmes or from external sources' (European Commission, 2006c, p. 9). ${ }^{17}$

${ }^{17}$ In essence the Commission proposed to dip into Research Framework funds, the Lifelong Learning Fund and the Structural Funds. Again the cheek of this needs to be recognised. The difficulty came when the 
The Proposal clearly had a difficult passage through the Council deliberations. When it finally emerged, in June 2007, the EIT looked very different (European Council, 2007).

The EIT in effect becomes a new Community institution, a conduit for funding with responsibility for the governance of networked public/private research activities. Made up of newly christened Knowledge Innovation Communities ${ }^{18}$ involving participants from at least 2 Member States plus a possible third country, the KICs are brought right back into the pan-European collaborative mode. Crucially too, the KICs have become nationally framed institutions operating under the governance of the EIT governing board. In essence the shift is from an EU University to a Community institution and, from a research perspective, the question then becomes what of the original ambition, significance and potential mechanisms of change remain?

It remains the case that funding is envisaged as coming from 'the $7^{\text {th }}$ Framework Programme for Research and Technological Development, the Competitiveness and Innovation Programme and the integrated Lifelong Learning Programme and the Structural Funds' (European Council, 2007, p. 2), although this would not survive Parliamentary scrutiny. Crucially too, the specificities of funding, the balance of public

European Parliament insisted that both the budget and its programmes were allocated and decided upon through Community processes and that money could not simply be taken from them for purposes which had not been agreed when they were allocated (Kubazova, 2007)

${ }^{18}$ In one respect the EIT did not survive the scrutiny of the European Parliament at all. Parliament called for it to be renamed The European Institute of Innovation and Technology while retaining the abbreviation of EIT. 
and private, of Member State and EU, in sum all of the aspects which could be expected to prove crucial to the success of the EIT, are not provided. Instead they are left conspicuously vague: the EIT will be financed 'through contributions from the budget of the European Union and other sources' (European Council, 2007, p. 14)

As an educational institution, the focus shifts to the KICs and their home contexts; degrees and diplomas will be conferred by the participating universities in accordance with their national regulations but can be additionally labelled or badged as EIT. ${ }^{19}$ In terms of funding, it will no longer be the case that the EIT will establish new conditions for accessing EU funds, rather it will be subject to the regulations pertaining to the specific source of funding, so for example, activities funded under the Framework Programmes will be subject to their regulations. While it remains the case that 'the KICs should aim at maximising the share of contributions from the private sector' (European Council, 2007, p. 4) there is no specified amount of private sector involvement. Intellectual Property Rights will remain with the KICs subject to contractual agreement between participants. It does however remain the case that each KIC must have a company and a university represented; the KIC cannot be either a university network or a source of funding for purely private sector R\&D.

\footnotetext{
${ }^{19}$ The position of the EIT in relation to degrees and diplomas is that they 'shall be awarded by participating universities in accordance with national rules and accreditation procedures. The agreement between the EIT and the KICs shall provide that these degrees and diplomas may also be labelled EIT-degrees and diplomas' (European Council, 2007, p. 11)
} 
At the same time, the foundations for future activities are established and the EIT will be an EU body with a legal identity which, within each of the Member States, 'shall enjoy the widest possible legal capacity accorded to legal persons under national legislation. In particular, it may acquire or dispose of moveable and immovable property and be a party to legal proceedings’ (European Council, 2007, p. 12)

As of January 2008, the Regulation for the establishment of the European Institute of Technology was awaiting the final scrutiny by the European Parliament in February 2008, after which the Commission would appoint the 18 member Governing Board. The aim was to have the Board in place by the summer of $2008^{20}$ and for selection of the first KIC’s to follow thereafter.

The Commission ambition was for an EIT as escape from national and institutional constraints, floating free of local commitment, with researchers and infrastructure seconded to a 'virtual' institution operating according to new allegiances and mandates. The EIT which emerged after long and difficult negotiation, had far more in common with the EU Research Framework networks than the ambition for a new kind of university. The story as explained to this point, confirms the significance of the national and the institutional in the EIT as EU sponsored innovation model. Nonetheless, the Commission ambition has not disappeared and discursively and materially, the role of the EIT within the EU Higher Education, Research and Innovation fields can be expected to

\footnotetext{
20 The Commissioner for Education and Culture, Jan Figel, announced to the European Parliament the four members of the ad hoc Identification Committee, which will recommend the names of the 18 member Governing Board. Members are to be 'independent members of the highest potential and prestige' able to 'provide a balanced expertise in business, research and education’ (European Commission, 2008, p. 2)
} 
continue to display the expected and predictable interactions between EU Lisbon Strategy models and initiatives, higher education and research institution dynamics and processes, global competitions for brains, national strategies, the politics of centralisation of capacity for economic development and the processes and legitimacy of EU integration.

\section{The EIT - A Research Agenda}

Having established the strategic selectivity of the discourses and practices of the EIT within the 'Growth and Jobs' Lisbon agenda and the conditions which produced significant modifications of the initial proposals, researchers are well placed to examine the processes and practices of the EIT as it is established.

Over the next year, as the EIT Governing Board is appointed, as it forms its strategic innovation plan and selects the first KICs, a research agenda can be developed which will make it possible to produce theoretically acute and empirically rich accounts of the significance and effects of the EIT itself and in its relations to the EU's strategic priorities

for innovation and the completion of the European Higher Education Area. The development of the EIT and the Europe of Knowledge will be of significant importance for consideration of the place of universities as sites of education, research and innovation in 'the area of tension between economy and culture, and between national ambitions and market adjustment’ (Gornitzka et al, 2007, p. 213)

So what should be the priorities for a research agenda? 
Analysis of the EIT as part of an EU innovation agenda will place a premium on analysing both vertical and horizontal dimensions of governance as innovation practices integrate, fuse and penetrate (Trondal, 2002). This will mean that the EIT as both Governing Board and as umbrella for KICs will need to be investigated in terms of the formation of their rules and practices and in relation to the determining factors which condition their formation. The rules and practices for the articulation of higher education, research and innovation will need to be investigated at the full range of scales and in relation to the interactions between public and private actors from universities and enterprises in different Member States and third countries. The first KICs for example should be addressed in terms of a network analysis which can situate them in terms of the stated ambitions of excellence regardless of pan-European or redistributive practices.

Secondly, given the evidence presented here on the strategic priorities of the European Commission, it will be important to retain a focus on the Commission role as coordinator of the EIT and its capacity to pursue policy entrepreneur and agenda amplification roles. In the selection of the Governing Board and KICs, the production of strategic innovation plans, the production of the contractual basis of the KICs and the connections made between the EIT's practices and the European Higher Education Area reforms, continuing analysis of the Commission will be vital. The production of the EIT signals a significant addition to the mechanisms and processes which are shunting the search for a new higher education settlement in particular directions. Consideration of the EIT as a new mechanism of disruption and destabilization will be essential to the analysis of its significance and outcomes. 
Thirdly, it will be important to look at each part of the education, research and innovation triangle. They need to be addressed individually and in their relations to one another. In terms of innovation and research, it will be important to pay attention to the sources of funding for research, the interactions with national research councils and the articulation of the range of interest groups, predominantly those of enterprise and venture capital. To an extent, the dimension of the EIT which suffered most during negotiation of the EIT Regulation, was education. The notion of the EIT as a university may have been something of a rhetorical distraction but nonetheless, it will be important to continue to analyse it in terms of Olsen's (2007) questions: what kind of university for what kind of society? It would appear that the EIT is to be a brand rather than a university, but nonetheless, universities are central to the KICs, the KICs will no doubt recruit and educate researchers and students and the content and practices of their education will need to be studied in terms of the cultural project which the Commission presented as an important part of the potential of the EIT. The EIT will be a factor in the home universities of the KIC networks and research will need to pay attention to the likely impacts on their identities, organisation, financing and propensity to cooperate and compete (Gornitzka et al, 2007; Olsen, 2007). It remains the case that the EIT even in its 'final' form, ${ }^{21}$ has the potential to be an additional factor in the processes of quality assurance and curriculum development, credit transfer and recognition of qualifications, transformations in governance and funding paradigms as part of the development of the

\footnotetext{
21 'Final' has to be treated extremely cautiously of course given the inbuilt mechanism and opportunities to revisit parts of the Commission agenda. It would be wise to consider final at least in terms of the current financial framework up to 2013 by which time evaluation of the first KICs will provide the opportunity to revisit the agenda.
} 
European Higher Education Area. And of course, the interactions between the education, research and innovation fields will be expected to provide valuable insights which can provide some material basis for the Commission notion of the EIT 'as a reference model and a competition-driven organisational form that will stimulate change by showing a living example of a different way of working' (European Commission, 2006b, p. 11).

Fourthly, there remains a distinct global dimension to the EIT project. While branded as a European institution, the extent to which it opens up research capacity both inside the EU and outside in the form of third countries and for organised national and trans-national capital (whether EU based or not) will become an important aspect of the research agenda.

Finally, the EIT as part of the EU, national and sub-national education, research and innovation frameworks, has the potential to contribute to developments within the broader political, economic`and social EU space. At the risk of opening up analytical and empirical areas which are beyond the scope of a study within the lifetime of even an extended research project, a research agenda will need to have the ambition with Tilly (1990) of looking from the EIT outwards to big structures, large processes and huge comparisons if we are to properly conceptualise the EIT outside of the university as an institution or research as a field. And of course, this is about seeing study of the EIT on a broader canvas which includes the study of institutional capacity building and EU integration but is as concerned to properly understand the place of the EIT within the fate of 'Growth and Jobs' Lisbon, EU strategies for capital accumulation and social development and the legitimacy of the EU itself. 


\section{References}

Amos, J. 2007. EU Money Geared to Smart Future. London: BBC News, 07.02.2007

Amos, J. 2007b. European Research Goes for Gold. London: BBC News, 27.02.2007.

Cafruny, A.W. and Ryner, J.M. 2007. Monetary Union and the Transatlantic and Social Dimensions of Europe’s Crisis. New Political Economy. 12, no. 2:141-165.

Collignon, S. 2006. The Lisbon Strategy, Macroeconomic Stability and the Dilemma of Governance with Governments. Boston and London: Harvard University and London School of Economics, www.stefancollignon.de/PDF/New\%20Lisbon\%20strategy.pdf

Corbett, A. 2003. Ideas, Institutions and Policy Entrepreneurs: towards a new history of higher education in the European Community. European Journal of Education 38, no. 3: 315-330.

Dale, R. 1989. The State and Education Policy., Milton Keynes: Open University Press.

Deutsche Welle. 2007. EU Secures Galileo Satellite Navigation Systems's Future. 26.11.07.

European Commission. 2005a. Working Together for Growth and Jobs: A New Start for the Lisbon Strategy, Communication from President Barroso in agreement with VicePresident Verheugen. Brussels: COM (2005) 24.

European Commission. 2005b. Mobilising the Brainpower of Europe: Enabling Universities To Make Their Full Contribution To The Lisbon Strategy. Brussels: COM (2005) 152.

European Commission. 2005c. A European Institute of Technology - Consultation Document. Brussels: European Commission

European Commission. 2005d. Modernising Education and Training: A Vital Contribution to Prosperity and Social Cohesion in Europe. Communication from the Commission. Brussels: COM (2005) 549.

European Commission. 2006a. Implementing the renewed partnership for growth and jobs: Developing a Knowledge Flagship: the European Institute of Technology. Brussels: COM (2006) 77. 
European Commission. 2006b. Communication from the Commission to the European Council - The European Institute of Technology: Further Steps Towards its Creation. Brussels: COM (2006) 276.

European Commission. 2006c. Proposal for a Regulation of the European Parliament and the Council Establishing the European Institute of Technology. Brussels: COM (2006) 604

European Commission. 2008.Setting the European Institute of Innovation and Technology (EIT) in motion: first steps towards the nomination of the members of the EIT Governing Board. Brussels: European Commission Press Release, IP/08/188.

European Council. 2000. Presidency Conclusions: European Council, 23 and 24 March 200., Brussels: Council of the European Union.

European Council. 2004. Education and Training 2010: The Success of the Lisbon Strategy Hinges on Urgent Reform. Joint Interim Report of the Council and the Commission. Brussels: Council of the European Union, March 2004.

European Council. 2005a. Presidency Conclusions: European Council, 22 and 23 March 2005. Brussels: Council of the European Union, 7619/1/05.

European Council. 2005b. Resolution of the Council and of the Representatives of the Governments of the Member States, meeting within the Council, on mobilising the brainpower of Europe: enabling higher education to make its full contribution to the Lisbon Strategy. Brussels: Official Journal of the European Union.

European Council. 2007. Outcome of Proceedings of the Council (Competitiveness) on 25 June 2007 - Proposal for a Regulation of the European Parliament and the Council Establishing the European Institute of Technology (EIT) - General Approach. Brussels: 11058/07.

European Parliament. 2007. Industry Committee Backs Creation of a European Institute of Innovation and Technology. European Parliament: Press Service 10.07.2007.

Gornitzka, A., Maassen, P., Olsen, J.P. and Stensaker, B. 2007. 'Europe of Knowledge.' Search for a New Pact, in Maassen, P. and Olsen, J.P. eds. 2007. University Dynamics and European Integration. Dordrecht: Springer.

Jessop, B. 2004. Critical Semiotic Analysis and Cultural Political Economy, Critical Discourse Studies 1, no. 2: 159-174.

Jones, C. 2007. McCreevy backs plans for single EU-US Market. ThePaliament.com

Kubazova, L. 2007. MEPs Threaten Red Light on Funds for EU's Technology Institute, Brussels: EUObserver. 29.05.2007 
Kok, W. 2004. Facing the Challenge Ahead: The Lisbon Strategy for Growth and Employment. Report from the High Level Group Chaired by Wim Kok. Luxembourg: Office for Official Publications of the European Communities.

Ludlow, P. 2005. Economic Governance in the European Union: The Spring European Council of 2005, EuroComment Briefing Note 3, no. 9.

Maassen, P. and Olsen, J.P. eds. 2007. University Dynamics and European Integration, Dordrecht: Springer.

Nyborg, P. 2008. Bologna and Lisbon - Two Processes or One, www.globalhighered.wordpress.com/page/2/.

Olsen, J.P. and Maassen, P. 2007. European Debates on the Knowledge Institution: The Modernization of the University at the European Level, in Maassen, P. and Olsen, J.P. eds. 2007. University Dynamics and European Integration. Dordrecht: Springer.

Olsen, J.P. 2007. The Institutional Dynamics of the European University, in Maassen, P. and Olsen, J.P. eds. 2007. University Dynamics and European Integration, Dordrecht: Springer.

Robertson, S.L. Forthcoming 2008. Embracing the Global: Crisis and the Creation of a New Semiotic Order to Secure Europe's Knowledge-Based Economy, in Fairclough, N., Wodak, R. and Jessop, B. eds. 2008. Education and the Knowledge-Based Economy in Europe. Netherlands: Sense Publishers.

Robertson, S.L. and Dale, R. 2003. Changing Geographies of Power in Education: the politics of rescaling and its contradictions. Paper presented to the joint BERA/BAICE conference on 'Globalisation, Culture and Education.' June 12 2003.

Science. 2006. Despite a Chilly Reception, the ‘European MIT’ Advances. Science 311, no. 5765: 1227.

The Guardian 2006. European Institute 'to rival MIT.' The Guardian.Wednesday February 22, 2006.

Tilly, C. 1990. Coercion, Capital and European States, A.D. 990-1990. Cambridge, Mass.: Blackwell

Traynor, I. 2007. Wealth Gap Grows and Solidarity Fades as Rebellion of Rich Spreads Across EU. The Guardian: 11.06.2007.

Trondal, J. 2002. The Europeanisation of Research and Higher Educational Policies: Some Reflections. Scandinavian Political Studies. 25, no. 4: 333-355.

Van Apeldoorn, B. 2006. The Lisbon Agenda and the Legitimacy Crisis of European Socio-Economic Governance: the Future of 'Embedded Neo-Liberalism, Paper 
Presented at the $4^{\text {th }}$ Convention of the Central and East European International Studies Association (CEEISA). University of Tartu, Estonia: 25-27 June 2006. 